\title{
How much has changed this year?
}

\author{
As 2021 winds down, we reflect on how our field has progressed with regard to diversity, equity, and inclusion \\ since 2020, and how far we still have to go.
}

T

he year 2020 felt like a transformative year, marked by a global pandemic and social upheaval. The murder of George Floyd by a Minneapolis police officer set off a wave of protests against racial injustice, and sparked conversations among scientists (and other professionals) about persistent racial inequities in their fields. Many science departments and societies issued commitments to improve the representation of Black scientists among their ranks. Now that another year has passed, we must reflect on how much progress has been made, and how to keep the momentum going.

In this issue of Nature Neuroscience, Lewis Wheaton provides an analysis of how representation of Black scientists at neuroscience conferences changed after the racial justice protests in 2020, noting that this is an area in which improving racial equity is under our immediate control. He finds that the overall representation of Black speakers had increased modestly, but that the overwhelming majority of neuroscience conferences still had zero Black speakers in the period following the summer of 2020. (The 2021 Glial Biology in Medicine conference, which the Nature Neuroscience editorial team helped to plan, only had one Black speaker among nineteen.) While improved, the status quo is clearly not acceptable.

As Wheaton describes, improving the representation of Black scientists will require intentional action. With regard to conferences, The American Society for Neurorehabilitation (ASNR) meeting, which he has helped to organize, may serve as an example to the field, having moved from 9.7\% to $18.8 \%$ Black speakers between 2019 and 2021. Since 2017, ASNR has required those proposing symposia to provide a statement on the diversity of the suggested speakers. This type of active reflection is quite effective, and must be engaged by hiring and admissions committees, awards panels, and other stakeholders, to improve equity overall.

We recognize that journals also have a long way to go toward representing the diversity of the field within our pages, and that we have an important role to play in the community. We do have a model for success from our efforts to improve gender diversity among our authors and reviewers. By applying this type of conscious effort, we hope to continue to diversify the racial, ethnic, and geographic make-up of our journal's contributors. As they write scientific papers, authors also should reflect on the diversity of the scientists whose work they choose to cite, and make sure that the contributions of scientists from historically excluded groups are not overlooked.

The failures to diversify neuroscience conferences that Wheaton describes, along with other short-comings of recent efforts, are especially disappointing because many scientists have an idealized vision of the field as a meritocracy. The conversations around racial and ethnic inequity in science that came to the forefront in 2020 pierced this illusion and showed us how much work remains to be done.

Science is a human endeavor, and as such reflects the flaws and failures of the societies that participate in it. And yet, science also remains a constant source of hope and inspiration. This year, we saw the roll-out of safe and effective vaccines against Covid-19, which were developed with unprecedented speed and international collaboration. Nature Neuroscience published remarkable discoveries about how SARS-CoV-2 infection affects brain vasculature, an EEG-based biomarker for improving epilepsy treatment, and a neuronal subpopulation that is selectively vulnerable to Alzheimer's disease, among many others. We're thrilled to be able to continue disseminating the most exciting neuroscience in the coming year.

Certainly compared to 2020, 2021 has felt quieter. Wheaton's Comment shows us the danger of being lulled into complacency as the tumult subsides. As 2022 approaches, we look forward to more activity and stimulation - returning to the office, meeting scientists in person at conferences, increasing outreach to underrepresented communities, and continuing to strive for equity and excellence. We wish everyone a healthy and happy 2022 !

Published online: 30 November 2021 https://doi.org/10.1038/s41593-021-00983-6 